\title{
Analisa Pembangkit Listrik Tenaga Diesel Gas dengan Menggunakan Bahan Bakar LNG dan Minyak Solar di PT Indonesia Power Unit Pembangkitan Bali
}

\author{
K G Trisna Upadana Putra ${ }^{1{ }^{\star}}$, I G B Wijaya Kusuma ${ }^{1)}$, M Sucipta ${ }^{1)}$ \\ 1) Jurusan Teknik Mesin, Fakultas Teknik, Universitas Udayana \\ Kampus Bukit Jimbaran, Bali 80362 \\ Email: trisnakomang586@gmail.com
}

doi: https://doi.org/10.24843/METTEK.2018.v04.i01.p05

\begin{abstract}
Abstrak
Permintaan energi listrik mengalami peningkatan, seiring peningkatan pertumbuhan populasi penduduk dan banyaknya industri. Tingginya permintaan energi listrik menjadi sebuah tantangan untuk produsen listrik, dalam memenuhi kebutuhan pelanggan akan energi listrik. Produsen listrik terbesar di Bali adalah PT. Indonesia Power UP Bali. Pembangkit yang dimiliki yaitu PLTDG dengan kapasitas produksi listrik 200 MW dioperasikan menggunakan bahan bakar gas LNG dan minyak solar (HSD/LFO). Dikarenakan penggunaan minyak solar dibatasi, maka PLTDG dioperasikan dengan gas LNG. Perbedaan bahan bakar yang digunakan mempengaruhi unjuk kerja dari pembangkit. Analisa unjuk kerja memberi gambaran dalam sisi keteknikan dan analisa BPP pembangkitan memberi gambaran dalam sisi keekonomian. Penelitian ini dilakukan dengan cara perhitungan menggunakan persamaan-persamaan unjuk kerja mesin diesel, kemudian dibandingkan unjuk kerja PLTDG menggunakan bahan bakar LNG dan minyak solar dan dianalisa secara keekonomian. Hasil yang didapat yaitu unjuk kerja PLTDG menggunakan minyak solar lebih besar tetapi dari sisi keekonomian hasil BPP PLTDG menggunakan gas LNG lebih ekonomis.
\end{abstract}

Kata Kunci: Diesel, PLTDG, LNG, HSD, minyak solar, unjuk kerja, BPP

\begin{abstract}
Demand for electric energy has increased, as population growth increases and the number of industries. The high demand for electrical energy becomes a challenge for electricity producers, in meeting the needs of customers for electrical energy. The largest power producer in Bali is PT. Indonesia Power UP Bali. The power plant owned by PLTDG with $200 \mathrm{MW}$ electricity production capacity is operated using LNG gas and diesel fuel (HSD/LFO). Due to the use of diesel fuel is limited, the PLTDG is operated with $L N G$ gas. The difference in fuel used affects the performance of the plant. Performance analysis gives an overview in terms of engineering and BPP analysis provides an overview of the economy side. This research is done by calculation using a diesel engine performance equation, and then compared the performance of PLTDG using $L N G$ and diesel fuel and analyzed economically. The results obtained are the performance of diesel-powered PLTDG larger but in terms of the economics of BPP $P L T D G$ results using LNG gas is more economical.
\end{abstract}

Keywords: Diesel, PLTDG, LNG, HSD, diesel fuel, performance, BPP

Penulis korespondensi

Email: trisnakomang586@gmail.com 


\section{PENDAHULUAN}

PT. Indonesia Power Unit Pembangkitan Bali memiliki 2 jenis pembangkit listrik yaitu Pembangkit Listrik Tenaga Gas (PLTG) dan Pembangkit Listrik Tenaga Diesel Gas (PLTDG). Pembangkit yang memiliki kapasitas produksi energi listrik yang besar yaitu PLTDG, dengan kapasitas produksi listrik sebesar 200 MW yang dapat dioperasikan menggunakan 3 jenis bahan bakar. Bahan bakar yang dapat digunakan untuk mengoprasikan mesin yaitu high speed diesel (HSD), light fuel oil (LFO) dan natural gas. PLTDG pada awal pengoprasiannya tahun 2015 menggunakan bahan bakar HSD dan LFO. Dikarenakan bahan bakar fosil (minyak solar) sangat terbatas dan tidak dapat diperbaharui serta tidak ramah dengan lingkungan, pembatasan penggunaan Bahan Bakar Minyak (BBM) untuk pembangkit harus diminimalkan dan terus dibatasi penggunaannya, kecuali untuk menjaga keandalan sistem.

Perbedaan karakteristik operasional pembangkit listrik berdasarkan bahan bakar yang digunakan akan mempengaruhi unjuk kerja dari pembangkit. Oleh karena itu dalam penelitian ini akan ditunjukkan unjuk kerja dari Pembangkit Listrik Tenaga Diesel Gas akibat pemakaian bahan bakar LNG dan minyak solar. Analisa terhadap unjuk kerja pembangkit akan memberi gambaran pemakaian bahan bakar LNG dan minyak solar dari sisi keteknikan, yang akan menunjukan ukuran-ukuran kuantitatif dari bahan bakar dan performansi dari PLTDG yang meliputi daya mesin, torsi, pemakaian bahan bakar spesifik dan efisiensi termal. Setelah mengetahui unjuk kerja dari pembangkit, maka dianalisa sistem pembangkit dari sisi keekonomian. Analisa kelayakan ekonomi akan menunjukkan besarnya BPP dari PLTDG dengan menggunakan bahan bakar gas LNG dan minyak solar. Dari analisa yang dilakukan, akan ditarik kesimpulan tentang bahan bakar yang harus digunakan untuk menghasilkan unjuk kerja mesin yang tinggi dan biaya yang lebih ekonomis.

\section{METODE}

Penelitian ini menganalisa perbandingan unjuk kerja dari PLTDG akibat pemakaian bahan bakar LNG dan minyak solar dan menganalisa kelayakan ekonomi PLTDG akibat pemakaian bahan bakar LNG dan minyak solar. Pengambilan data dilakukan pada interfal waktu operasi mesin minimal 12 jam operasi dan analisa keekonomian hanya membandingkan harga bahan bakar yang dikonsumsi mesin per kWh.

Metoda penelitian ini adalah mengkaji secara termodinamika terhadap unjuk kerja pembangkit yang meliputi daya efektif, torsi, konsumsi bahan bakar, efisiensi termal, dan analisis keekonomiannya. Berdasarkan analisa yang dilakukan, akan ditarik kesimpulan tentang bahan bakar yang harus digunakan untuk menghasilkan unjuk kerja mesin yang tinggi dan biaya penyediaan pembangkit yang lebih rendah. Data primer yang langsung diambil dari hasil observasi lapangan, dalam hal ini adalah daya output generator, nilai kalor bahan bakar, laju alir massa bahan bakar yang dikonsumsi mesin, serta spesifikasi mesin pembangkit yang digunakan dalam pelaksanaan penelitian. Kumpulan data teoritis yang diperoleh dari berbagai referensi pustaka, baik berupa buku, jurnal/artikel, tabel maupun data laporan tahunan dari instansi yang berhubungan dengan penelitian ini. Data yang diambil adalah daya output generator dan laju alir massa bahan bakar yang dikonsumsi mesin. Pengolahan data dilakukan berdasarkan analisa data yang diperoleh untuk mengkaji secara termodinamika unjuk kerja pembangkit yang meliputi daya efektif, torsi, konsumsi bahan bakar, efisiensi termal, dan analisis keekonomiannya.

\section{HASIL DAN PEMBAHASAN \\ 3.1 Daya Efektif}

Daya mesin merupakan daya yang dihasilkan mesin untuk mengatasi beban yang diberikan. Daya yang dihasilkan pada mesin diesel yang dikopel dengan generator listrik dapat dihitung berdasarkan daya keluaran generator listrik dan dinyatakan sebagai daya 
efektif pada generator $\left(N_{e}\right)$.Hasil perolehan data pada PLTDG 18V50DF unit 12 untuk perhitungan daya efektif yang dihasilkan pembangkit dengan menggunakan bahan bakar LNG dan minyak solar dapat dilihat pada Table 1 di bawah ini.

Tabel 1 Data Untuk Perhitungan Daya Efektif

\begin{tabular}{ccccc}
\hline \multirow{2}{*}{ No } & \multirow{2}{*}{ Data } & Dual Fuel & Single Fuel & \multirow{2}{*}{ Satuan } \\
\cline { 3 - 4 } 1 & Daya generator $\left(N_{\text {gen }}\right)$ & 15654000 & 16844000 & \multirow{2}{*}{ Watt } \\
\hline 2 & Efisiensi generator $\left(\eta_{\text {gen }}\right)$ & & 90 & $\%$ \\
\hline 3 & Efisiensi transmisi $\left(\eta_{\text {trans }}\right)$ & & 95 & $\%$ \\
\hline
\end{tabular}

Berdasarkan Tabel 1 di atas, maka dapat disampaikan bahwa apabila nilai output generator $\left(\mathrm{N}_{\text {gen }}\right)$ yang dihasilkan semakin besar dan nilai $\eta_{\text {generator, }} \eta_{\text {transmisi }}$ bernilai tetap maka nilai daya efektif ( $\mathrm{Ne}$ ) akan meningkat. Semakin besar daya output generator yang dihasilkan PLTDG baik menggunakan bahan bakar LNG dan minyak solar, maka daya efektif yang dihasilkan akan semakin besar. Pada perhitungan daya efektif PLTDG pada saat dual fuel didapat daya efektif sebesar 18308771,93 Watt, sedangkan besar daya efektif PLTDG pada saat mode single fuel sebesar 19700584,80 Watt. Berdasarkan hasil perhitungan data PLTDG unit 12 pada mode single fuel dan dual fuel selama 24 jam didapat nilai rata-rata daya efektif masing-masing sebesar 19461894,74W dan 17272093,57W. Maka dapat disimpulkan daya efektif yang dihasilkan PLTDG unit 12 dengan menggunakan bahan bakar LNG lebih rendah dibandingkan daya efektif yang dihasilkan PLTDG dengan menggunakan bahan bakar minyak solar (HSD), selisih nilai rata-rata daya efektif yang dihasilkan sebesar 2189801,17W, hal ini menunjukkan bahwa besar nilai output generator sangat berpengaruh dengan daya efektif yang dihasilkan pembangkit.

\subsection{Torsi}

Torsi merupakan gaya yang bekerja pada poros engkol (crankshaft). Hasil perolehan data pada PLTDG 18V50DF unit 12 untuk perhitungan torsi yang dihasilkan pembangkit dengan menggunakan bahan bakar LNG dan minyak solar dapat dilihat pada Table 2 di bawah.

Tabel 2 Data Untuk Perhitungan Torsi.

\begin{tabular}{clrcc}
\hline \multirow{2}{*}{ No } & \multirow{2}{*}{ Data } & \multicolumn{2}{c}{ Nilai } & \multirow{2}{*}{ Satuan } \\
\cline { 3 - 4 } & & Dual Fuel & Single Fuel & \\
\hline 1 & Daya generator $\left(N_{\text {gen }}\right)$ & 15654000 & 16844000 & Watt \\
\hline 2 & Daya efektif $\left(N_{e}\right)$ & 18308771,93 & 19700584,80 & Watt \\
\hline 3 & Putaran mesin $(\mathrm{n})$ & \multicolumn{2}{c}{500} & rpm \\
\hline
\end{tabular}

Berdasarkan Tabel 2 di atas nilai torsi bergantung pada besarnya nilai daya efektif (Ne) yang dihasilkan mesin pembangkit dan putaran mesin (n). Karena dalam pengujian ini putaran mesin dijaga tetap konstan, maka torsi berbanding lurus dengan daya efektif yang diberikan, semakin besar daya efektif yang diberikan mesin baik menggunakan bahan bakar LNG maupun minyak solar, maka torsi yang dihasilkan akan semakin besar. Pada perhitungan torsi 
PLTDG pada saat mode dual fuel didapat nilai torsi sebesar 349849,145 Nm, sedangkan besar nilai torsi PLTDG pada saat mode single fuel sebesar 376444,295 Nm. Berdasarkan hasil perhitungan data PLTDG unit 12 pada mode single fuel dan dual fuel selama 24 jam didapat nilai rata-rata torsi masing-masing sebesar 371883,339 Nm dan $330040.004 \mathrm{Nm}$, maka dapat disimpulkan torsi yang dihasilkan PLTDG unit 12 dengan menggunakan bahan bakar LNG lebih rendah dibandingkan torsi yang dihasilkan PLTDG dengan menggunakan bahan bakar minyak solar (HSD), selisih nilai rata-rata torsi yang dihasilkan sebesar 41843,334 Nm, hal ini menunjukkan bahwa besar nilai daya efektif sangat berpengaruh dengan torsi yang dihasilkan pembangkit.

\subsection{Specific Fuel Consumption (SFC)}

Specific fuel consumption ( $s f$ ) adalah jumlah bahan bakar yang dipakai mesin untuk menghasilkan daya efektif selama 1 jam atau konsumsi bahan bakar spesifik adalah jumlah bahan bakar yang dikonsumsi per satuan daya kali waktu. Adapun data yang didapat untuk mengukur SFC dapat dilihat pada Tabel 3 di bawah ini.

Tabel 3. Data Untuk Perhitungan Specific Fuel Consumption

\begin{tabular}{|c|c|c|c|c|}
\hline \multirow{2}{*}{ No } & \multirow{2}{*}{ Data } & \multicolumn{2}{|c|}{ Nilai } & \multirow{2}{*}{ Satuan } \\
\hline & & Dual Fuel & Single Fuel & \\
\hline 1 & Daya efektif $\left(N_{e}\right)$ & 18308771,93 & 19700584,80 & Watt \\
\hline 2 & Laju alir massa bb LNG ( $\mathrm{m}_{\text {gasing }}$ ) & 2531 & & $\mathrm{~kg} / \mathrm{jam}$ \\
\hline 3 & Laju alir massa bb solar $\left(\mathrm{m}_{\text {solar }}\right)$ & & 3139 & $\mathrm{~kg} / \mathrm{jam}$ \\
\hline
\end{tabular}

Berdasarkan Tabel 3, semakin tinggi daya efektif yang dihasilkan PLTDG baik menggunakan bahan bakar LNG dan minyak solar, maka berdasarkan perhitungan nilai $s f c$ yang dihasilkan akan semakin rendah dan sebaliknya jika daya efektif yang dihasilkan mesin rendah maka nilai sfc yang dihasilkan akan tinggi. Hasil perhitungan jumlah bahan bakar spesifik $(s f c)$ yang dikonsumsi mesin PLTDG unit 12 dengan menggunakan gas LNG (dual fuel) bernilai $0,138 \frac{\mathrm{kg}}{\mathrm{kWh}}$, lebih rendah dibandingkan nilai sfc PLTDG dengan menggunakan bahan bakar minyak solar (single fuel) yaitu sebesar $0,159 \frac{\mathrm{kg}}{\mathrm{kWh}}$. Berdasarkan hasil perhitungan data PLTDG unit 12 pada mode single fuel dan dual fuel selama 24 jam didapat nilai rata-rata $s f c$ masing-masing sebesar $0,164 \frac{\mathrm{kg}}{\mathrm{kWh}}$ dan $0,142 \frac{\mathrm{kg}}{\mathrm{kWh}}$, maka dapat disimpulkan $s f c$ yang dihasilkan PLTDG unit 12 dengan menggunakan bahan bakar LNG lebih rendah dibandingkan $s f c$ yang dihasilkan PLTDG dengan menggunakan bahan bakar minyak solar (HSD), selisih nilai rata-rata $s f c$ yang dihasilkan sebesar $0,022 \frac{\mathrm{kg}}{\mathrm{kwh}}$, hal tersebut terjadi dikarenakan jumlah bahan bakar gas LNG yang dikonsumsi oleh mesin PLTDG pada saat mode dual fuel lebih rendah dibandingkan jumlah bahan bakar minyak solar yang dikonsumsi mesin PLTDG pada mode single fuel.

\subsection{Efisiensi Termal $\left(\eta_{t h}\right)$}

Efisiensi termal adalah ukuran besarnya pemanfaatan energi panas yang tersimpan dalam bahan bakar untuk diubah menjadi daya efektif oleh mesin pembakaran dalam. Data yang digunakan untuk menghitung efisiensi termal mesin PLTDG unit 12, dapat dilihat pada Tabel 4 di bawah ini. 
Tabel 4. Data Untuk Perhitungan Efisiensi Termal.

\begin{tabular}{clccc}
\hline \multirow{2}{*}{ No } & \multicolumn{1}{c}{ Data } & \multicolumn{2}{c}{ Nilai } & \multirow{2}{*}{ Satuan } \\
\cline { 3 - 4 } & & Dual Fuel & Single Fuel & \\
\hline 1 & Daya efektif $\left(\mathrm{N}_{\mathrm{e}}\right)$ & 18308,77 & 19700,58 & $\mathrm{~kW}$ \\
\hline 2 & Laju alir massa bb LNG $\left(\mathrm{m}_{\text {gaslng }}\right)$ & 2531 & & $\mathrm{~kg} / \mathrm{jam}$ \\
\hline 3 & Laju alir massa bb solar $\left(\mathrm{m}_{\text {solar }}\right)$ & \multicolumn{2}{c}{3139} & $\mathrm{~kg} / \mathrm{jam}$ \\
\hline 4 & Nilai kalor bawah bb.LNG $\left(\mathrm{Q}_{\mathrm{gasLNG}}\right)$ & \multicolumn{2}{c}{49785} & $\mathrm{~kJ} / \mathrm{kg}$ \\
\hline 5 & Nilai kalor bawah bb.Solar $\left(\mathrm{Q}_{\text {solar }}\right)$ & 42877,484 & $\mathrm{~kJ} / \mathrm{kg}$ \\
\hline
\end{tabular}

Berdasarkan Tabel 4 dapat disampaikan bahwa nilai efisiensi termal bergantung pada besarnya nilai daya efektif (Ne) yang dihasilkan mesin pembangkit, jumlah bahan bakar yang dikonsumsi mesin dan nilai kalor bahan bakar (LHV) Semakin besar daya efektif yang dihasilkan PLTDG baik menggunakan bahan bakar LNG dan minyak solar, maka efisiensi termal $\left(\eta_{t h}\right)$ pembangkit yang dihasilkan akan semakin besar. Pada perhitungan efisiensi termal $\left(\eta_{t h}\right)$ PLTDG pada pukul 01.00 WITA saat mode dual fuel didapat nilai efisiensi termal sebesar 52,308\%, sedangkan besar nilai efisiensi termal $\left(\eta_{\text {th }}\right.$ ) PLTDG pada saat mode single fuel sebesar 52,694\%. Berdasarkan hasil perhitungan data PLTDG unit 12 pada mode single fuel dan dual fuel selama 24 jam didapat nilai rata-rata efisiensi termal masingmasing sebesar 51,729\% dan 51,550\%. Maka dapat disimpulkan efisiensi termal yang dihasilkan PLTDG unit 12 dengan menggunakan bahan bakar LNG lebih rendah dibandingkan efisiensi termal yang dihasilkan PLTDG dengan menggunakan bahan bakar minya solar (HSD), selisih nilai rata-rata efisiensi termal yang dihasilkan sebesar $0,179 \%$, hal ini menunjukkan bahwa tinggi atau rendahnya nilai efisiensi termal sangat dipengaruhi dengan nilai kalor bawah (LHV) suatu bahan bakar dan jumlah bahan bakar yang dikonsumsi $\operatorname{mesin}(\dot{m})$.

\subsection{Analisa Keekonomian}

Analisa keekonomian diperhitungkan berdasarkan variasi harga HSD terhadap BPP Pembangkitan Listrik (Rp/kWh). Berdasarkan perhitungan biaya pokok penyediaan pembangkitan PLTDG unit 12 dengan menggunakan bahan bakar gas LNG dan minyak solar disajikan pada Tabel 5. Berdasarkan Hasil perhitungan biaya pokok penyediaan (BPP) PLTDG unit 12 dengan menggunakan bahan bakar gas dan minyak solar, maka faktor yang mempengaruhi BPP pembangkit yaitu jumlah bahan bakar yang digunakan mesin untuk menghasilkan daya efektif selama 1 jam (SFC) dan harga bahan bakar yang digunakan. Harga bahan bakar minyak solar (HSD) lebih tinggi dari pada harga bahan bakar gas LNG.

Hasil perhitungan BPP PLTDG unit 12 dengan menggunakan bahan bakar minyak solar (HSD) lebih besar dari pada BPP PLTDG unit 12 dengan menggunakan bahan bakar gas LNG (dual fuel), hal itu dikarenakan jumlah bahan bakar yang dikonsumsi PLTDG pada mode dual fuel lebih rendah dari pada jumlah bahan bakar yang dikonsumsi PLTDG pada saat mode single fuel dan harga bahan bakar gas LNG yang rendah dibandingkan minyak solar.

Tabel 5. Hasil Perhitungan Biaya Pokok Penyediaan (BPP) PLTDG unit 12

No Mode Pengoperasian Mesin BPP Pembangkitan Listrik (Rp/kWh)




\begin{tabular}{lll}
\hline 1 & Gas LNG+Solar (Dual Fuel) & Rp. $1.079,266 / \mathrm{kWh}$ \\
\hline 2 & Minyak Solar (Single Fuel) & Rp. $1.398,201 / \mathrm{kWh}$ \\
\hline
\end{tabular}

\section{SIMPULAN}

Berdasarkan data dan analisa data, disimpulkan bahwa unjuk kerja pembangkit PLTDG dengan menggunakan bahan bakar minyak solar lebih baik dibandingkan dengan menggunakan bahan bakar gas LNG dimana nilai daya efektif, torsi, $S F C$ dan efisiensi termal yang dihasilkan lebih tinggi dibandingkan unjuk kerja menggunakan gas LNG. Dari kajian keekonomian, yaitu penggunaan minyak solar (HSD) sebagai bahan bakar pembangkit tidak menguntungkan lagi apabila harga bahan bakar HSD sudah berharga di atas Rp 7500/liter dan harga jual listrik PLN masih Rp.1467,28/kWh. Hal yang harus dilakukan adalah dengan mengganti bahan bakar minyak solar (HSD) dengan bahan bakar gas LNG. Hal ini akan mengurangi subsidi bahan bakar dan subsidi pembangkit listrik PLN.

\section{DAFTAR PUSTAKA}

[1] Ahmad, A. S. (2017). Studi Eksperimen Unjuk Kerja Mesin Diesel Sistem Dual Fuel Dengan Variasi Tekanan Penginjeksian Pada Injektor Mesin Yanmar Tf55 R. Skripsi Program Studi Teknik Mesin, Fakultas Teknik, Institut Teknologi Sepuluh Nopember, Surabaya.

[2] Arismunandar, W. dan Tsuda, K. (1986). Motor Diesel Putaran Tinggi (6 ed.). Jakarta: PT. Pradnya Paramita.

[3] Cengel, Y. A. dan Boles, M. A. (2006). Thermodynamics An Engineering Approach (5 ed.). United States: McGraw-hill Companies.

[4] Culp, A. W. Jr. (1989). Prinsip-Prinsip Konversi Energi. Jakarta: Erlangga.

[5] Jones, J.B. dan Dugan. R. E. (1995). Engineering Thermodynamics. Prentice Hall. USA.

[6] Nuswantara, M. R. P. dan Wibawa, W. P. G. (2014). Regasification of LNG (Liquefied Natural Gas). Jurnal Teknik Pomits, Vol. 3, B-149-B-152.

[7] Sanjaya. S. (2017). Kajian Teknis Antara Penggunaan Bahan Bakar HSD dan MFO Sebagai Bahan Bakar Alternatif Pengganti LNG di PLTDG PT. Indonesia Power UPJP Bali. Skripsi Program Studi Teknik Mesin, Fakultas Teknik, Universitas Udayana, Bali.

[8] Sitepu, T. (2009). Kajian Eksprimental Pengaruh Bahan Aditif Octane Boster Terhadap Nilai Kalor Bahan Bakar Solar Jurnal Dinamis, Vol. II, 11-18.

[9] Suhartanta, Z. A. (2008). Pemanfaatan Minyak Jarak Pagar Sebagai Bahan Bakar Alternatif Mesin Diesel Jurnal Penelitian Saintek, Vol. 13, 19-46. 